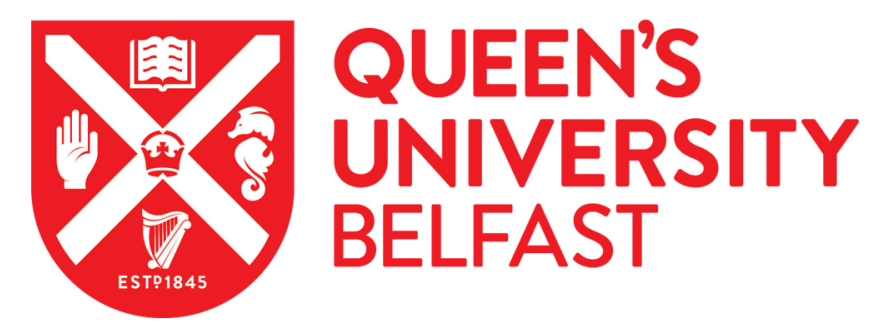

\title{
The absence of creativity in Feist and the computational process
}

Warner, J. (2010). The absence of creativity in Feist and the computational process. Journal of the American Society for Information Science and Technology, 61(11), 2324-2336. https://doi.org/10.1002/asi.21395

Published in:

Journal of the American Society for Information Science and Technology

Document Version:

Early version, also known as pre-print

Queen's University Belfast - Research Portal:

Link to publication record in Queen's University Belfast Research Portal

Publisher rights

(c) 2010 ASIS\&T.

This is the pre-peer reviewed version of this article, which has been published in final form at doi: 10.1002/asi.21395. This article may be used for non-commercial purposes in accordance with Wiley Terms and Conditions for Self-Archiving.

\section{General rights}

Copyright for the publications made accessible via the Queen's University Belfast Research Portal is retained by the author(s) and / or other copyright owners and it is a condition of accessing these publications that users recognise and abide by the legal requirements associated with these rights.

Take down policy

The Research Portal is Queen's institutional repository that provides access to Queen's research output. Every effort has been made to ensure that content in the Research Portal does not infringe any person's rights, or applicable UK laws. If you discover content in the Research Portal that you believe breaches copyright or violates any law, please contact openaccess@qub.ac.uk. 
This is a preprint of an article accepted for publication in Journal of the American Society for Information Science and Technology copyright (๐ 2010 (American Society for Information Science and Technology).

\title{
The absence of creativity in Feist and the computational process
}

\author{
Julian Warner \\ Queen's School of Management \\ The Queen's University of Belfast \\ Northern Ireland \\ United Kingdom
}

j.warner@qub.ac.uk

\begin{abstract}
.
The decision of the United States Supreme Court in 1991 in Feist Publications, Inc. v. Rural Tel. Service Co. affirmed originality as a constitutional requirement for copyright. Originality has a specific sense and is constituted by a minimal degree of creativity and independent creation.

The not original is the more developed concept within the decision. It includes the absence of a minimal degree of creativity, as a major constituent. Different levels of absence of creativity are also distinguished, from the extreme absence of creativity to insufficient creativity. There is a gestalt effect of analogy between the delineation of the not original and the concept of computability.

More specific correlations can be found within the extreme absence of creativity. '[S]o mechanical' in the decision can be correlated with an automatic mechanical procedure and clauses with a historical resonance with understandings of computability as what would naturally be regarded as computable. The routine within the extreme absence of creativity can be regarded as the product of a computational process.
\end{abstract}

The concern of this paper is with rigorously establishing an understanding of the extreme absence of creativity, primarily through the correlations with aspects of computability. The understanding established is consistent with the other elements of the not original. It also revealed as testable under real world conditions.

The possibilities for understanding insufficient creativity, a minimal degree of creativity, and originality, from the understanding developed of the extreme absence of creativity, are indicated.

\section{Introduction}

The decision of the United States Supreme Court, Feist v. Rural (Feist Publications, Inc. v. Rural Tel. Service Co., Inc., 1991), was characterized as 'a defining event for copyright in the information age' (Goldstein, 1991, p.118), shortly after its publication. Subsequently, it came to be viewed as the 'now-governing case' (Nimmer \& Nimmer, 1978/2009, 13.01), with significant effects beyond its original jurisdiction (Narayanan, 1994). The significance of the decision arises primarily from its denial of the labor or sweat of the brow interpretation of copyright and the affirmation of originality as a constitutional requirement for copyright protection (Feist Publications, Inc. v. Rural Tel. Service Co., Inc., 1991, p.346). 
Originality has a specific sense in copyright.

Original, as the term is used in copyright, means only that the work was independently created by the author (as opposed to copied from other works), and that it possesses at least some minimal degree of creativity. (Feist Publications, Inc. v. Rural Tel. Service Co., Inc., 1991, p.345).

The original is, then, constituted by two differentiated elements, independent creation and some minimal degree of creativity. The positive concern with the original in the opinion is more to do with originality as a constitutional requirement for copyright than with further delineating originality itself or its constituent elements.

The absence of originality, or the not original, rather than originality itself, is the more extensively developed concept. Towards the conclusion of the opinion, the question is posed, 'whether Rural selected, coordinated, or arranged these uncopyrightable facts in an original way' (Feist Publications, Inc. v. Rural Tel. Service Co., Inc., 1991, p.362). The opinion subsequently states:

We conclude that the names, towns, and telephone numbers copied by Feist were not original to Rural, and therefore were not protected by the copyright in Rural's combined white and yellow pages directory. (Feist Publications, Inc. v. Rural Tel. Service Co., Inc., 1991, p.363) [emphasis added]

Between the question and the conclusion, processes and products which lack the requisite minimal degree of creativity and independent creation are extensively delineated (pp.362363). The position of the delineation implies that it forms the determining component for the decision. It is this delineation that we understand primarily as the not original within the opinion.

The not original, conversely to and consistently with the original, is a compound concept. The absence of some minimal degree of creativity forms one constituent. The necessity for creativity is first positively asserted: 'the Constitution mandates some minimal degree of creativity' (Feist Publications, Inc. v. Rural Tel. Service Co., Inc., 1991, p.363). Secondly, three separate statements directly invoke the absence of a minimal degree of creativity:

\footnotetext{
'do not satisfy the minimum constitutional standards for copyright protection' 'lacks the modicum of creativity necessary [for] copyrightable expression' 'does not possess the minimal creative spark required by the Copyright Act and the Constitution'

(Feist Publications, Inc. v. Rural Tel. Service Co., Inc., 1991, p.363)
}

The other constituent of the not original is the absence of independent creation and this is rather indirectly indicated.

Rural did not truly 'select' to publish the names and telephone numbers of its subscribers; rather, it was required to do so by the Kansas Corporation Commission as part of its monopoly franchise. ... Accordingly, one could plausibly conclude that this selection was dictated by state law, not by Rural. (Feist Publications, Inc. v. Rural Tel. Service Co., Inc., 1991, p.362). 
The determination of the process of selection by an outside body precludes the presence of independent creation, also indicated by the to in 'not original to' (p.363) (The written verbal analysis of the opinion is accompanied by a more fully graphic correlate; see Figure 1).

Descriptive clauses which refer to the absence of a minimal degree of creativity are further and more closely connected with a specific degree of absence of creativity. '[S]o mechanical or routine' is immediately qualified by, 'as to require no creativity whatsoever' (Feist Publications, Inc. v. Rural Tel. Service Co., Inc., 1991, p.362). '[E]ntirely typical ... garden-variety' is connected to the clause, 'devoid of even the slightest trace of creativity' (p.362). '[C]ould not be more obvious ... most basic information' is linked to 'insufficient creativity' (p.363). Clauses with a historical resonance-'an age-old practice, firmly rooted in tradition and so commonplace that it has come to be expected as a matter of course ... practically inevitable ... time-honored tradition' (p.363) — are introduced by the clause, 'nothing remotely creative' (p.363).

The particular clauses which give degrees of absence of creativity can gathered into two groups. '[N]o creativity whatsoever', 'devoid of even the slightest trace of creativity', and 'nothing remotely creative' (Feist Publications, Inc. v. Rural Tel. Service Co., Inc., 1991, pp.362-363) can be gathered together under the extreme absence of creativity. The grouping is analytically useful, but not essential to the subsequent argument, and can be represented graphically as a dark overlay. The remaining clause, 'insufficient creativity' (p.363), can be considered as a category in itself, with the description, insufficient creativity, retained for the category and represented as a light overlay (See Figure 1). Both degrees of absence determine that a compilation is not original.

The invocation of the absence of independent creation, the other constituent of the not original, can be connected with one of the clauses within the complete absence of creativity. The paragraph in which the absence of independent creation is invoked is sharply separated from the preceding paragraph dealing with insufficient creativity: 'We note in passing that the selection featured in Rural's white pages may also fail the originality requirement for another reason' (Feist Publications, Inc. v. Rural Tel. Service Co., Inc., 1991, p.363). It is more continuous with the subsequent paragraph containing the historical clauses characterizing the extreme absence of creativity. The subsequent paragraph opens, 'Nor can Rural claim originality in its coordination and arrangement' (Feist Publications, Inc. v. Rural Tel. Service Co., Inc., 1991, p.362), with the opening '[n]or' implying some difference but also a continuity. Differences are revealed in the explicit concern with coordination and arrangement, rather than with selection, and in the presence of independent creation: 'no one disputes that Rural undertook the task of alphabetizing the names itself' (p.362). Continuity must then reside in the extreme absence of creativity: '... nothing remotely creative' (p.363). 


\begin{tabular}{|c|c|c|c|c|c|c|c|}
\hline Originality & $\begin{array}{l}\text { Constituent } \\
\text { concept of the } \\
\text { original }\end{array}$ & |Not original & $\begin{array}{l}\text { Constituent } \\
\text { concept of the } \\
\text { not original }\end{array}$ & \begin{tabular}{|l} 
Corresponding \\
clauses within the \\
not original
\end{tabular} & Delineation & \begin{tabular}{|l} 
Degree of \\
absence of \\
creativity
\end{tabular} & Not original \\
\hline \multirow{5}{*}{$\begin{array}{l}\text { Original, as the } \\
\text { term is used in } \\
\text { copyright, } \\
\text { means only that } \\
\text { the work was } \\
\text { independently } \\
\text { created by the } \\
\text { author (as } \\
\text { opposed to } \\
\text { copied from } \\
\text { other works), } \\
\text { and that it } \\
\text { possesses at } \\
\text { least some } \\
\text { minimal degree } \\
\text { of creativity. }\end{array}$} & \multirow{4}{*}{$\begin{array}{l}\text { Some minimal } \\
\text { degree of } \\
\text { creativity }\end{array}$} & \multirow{5}{*}{\begin{tabular}{|} 
The question that \\
remains is \\
whether Rural \\
selected, \\
coordinated, or \\
arranged these \\
uncopyrightable \\
facts in an \\
original way
\end{tabular}} & \multirow{3}{*}{\begin{tabular}{|l} 
Not \\
possessing \\
some minimal \\
degree of \\
creativity
\end{tabular}} & $\begin{array}{l}\text { the Constitution } \\
\text { mandates some } \\
\text { minimal degree of } \\
\text { creativity }\end{array}$ & so mechanical or routine & \begin{tabular}{|l} 
as to require no \\
creativity \\
whatsoever
\end{tabular} & \multirow{5}{*}{\begin{tabular}{|} 
We conclude \\
that the names, \\
towns, and \\
telephone \\
numbers copied \\
by Feist were \\
not original to \\
Rural
\end{tabular}} \\
\hline & & & & \begin{tabular}{||l} 
do not satisfy the \\
minimum \\
constitutional \\
standards for \\
copyright protection
\end{tabular} & $\begin{array}{l}\text { entirely typical .... end product } \\
\ldots \text { garden-variety }\end{array}$ & $\mid \begin{array}{l}\text { devoid of even } \\
\text { the slightest } \\
\text { trace of creativity }\end{array}$ & \\
\hline & & & & \begin{tabular}{|l} 
lacks the modicum \\
of creativity \\
necessary [for] \\
copyrightable \\
expression
\end{tabular} & $\begin{array}{l}\text { 'selection' of a sort ... could not } \\
\text { be more obvious ... the most } \\
\text { basic information }\end{array}$ & $\begin{array}{l}\text { insufficient } \\
\text { creativity }\end{array}$ & \\
\hline & & & \begin{tabular}{|l} 
Not \\
independently \\
created by the \\
author.
\end{tabular} & $\begin{array}{l}\text { may also fail the } \\
\text { originality } \\
\text { requirement for } \\
\text { another reason }\end{array}$ & $\begin{array}{l}\text { did not truly 'select' ... dictated } \\
\text { by state law }\end{array}$ & $\mid \begin{array}{l}\text { |... nothing } \\
\text { remotely creative }\end{array}$ & \\
\hline & $\begin{array}{l}\text { Independently } \\
\text { created by the } \\
\text { author. }\end{array}$ & & \begin{tabular}{|l} 
Not \\
possessing \\
some minimal \\
degree of \\
creativity
\end{tabular} & \begin{tabular}{||l||} 
does not possess \\
the minimal creative \\
spark required by the \\
Copyright Act and \\
the Constitution
\end{tabular} & $\begin{array}{l}\text { an age-old practice, firmly } \\
\text { rooted in tradition and so } \\
\text { commonplace that it has come } \\
\text { to be expected as a matter of } \\
\text { course .... practically inevitable } \\
\text {... time-honored tradition }\end{array}$ & \begin{tabular}{|l} 
nothing remotely \\
creative
\end{tabular} & \\
\hline
\end{tabular}

Figure 1. Analysis of the opinion. 
The clauses characterizing not original processes and products of selection, coordination, and arrangement, and their resulting products, can be considered as a whole, with their order preserved:

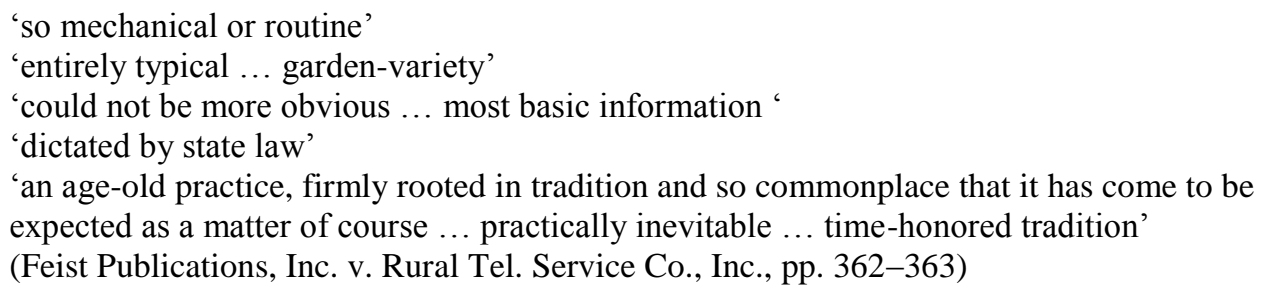

The opening clause, 'so mechanical or routine', is the dominant clause, or kernel. Subsequent clauses amplify the meaning of the 'so mechanical or routine' without exceeding or transgressing it. All the constituent content bearing terms have ordinary discourse, rather than technical, meanings and can be understood in their central ordinary discourse senses (Warner, 2010).

A strong analogy can be discerned between the characterization of the processes and products which lack a modicum of creativity and a concept of compelling contemporary significance and highly relevant to the decision, the concept of computability. Computability was classically characterized by Kurt Gödel in 1946:

It seems that this importance [of Turing's computability] is largely due to the fact that with this concept one has for the first time succeeded in giving an absolute definition of an interesting epistemological notion, i.e., one not depending on the formalism chosen. In all other cases treated previously, such as demonstrability or definability, one has been able to define them only relative to a given language, and for each individual language it is clear that the one thus obtained is not the one looked for. (Gödel, 1946/2004, p.84)

The relation of the clauses in the opinion to the characterization of computability can first be sensed as a gestalt, or overall, effect of correspondence or analogy. The analogy with computability offers the possibility of a further elucidation of the absence of a modicum of creativity, by referring it to something more definitively understood.

The clauses in the opinion and the characterization of computability have no substantive words in common but more specific verbal and then conceptual correlations can be found between particular clauses in the opinion and aspects of computability. '[M]echanical' in 'so mechanical' can be correlated with a mechanical procedure or algorithm and 'so mechanical' (Feist Publications, Inc. v. Rural Tel. Service Co., Inc., p.363) as a whole with an automatic mechanical procedure. The clauses in the opinion with a historical resonance, from 'an age-old practice' to 'time-honored tradition' (pp. 362-363), can be correlated with a foundation for the concept of computability, with what would naturally be regarded as computable. Identifying specific correlations should have the effect of strengthening the overall analogy.

Identifying the degree of absence of creativity with which the more specifically correlated clauses in the opinion are connected can also refine the analogy. '[S]o mechanical' and the clauses with a historical resonance could both be gathered together under the extreme 
absence of creativity. The other element of the extreme absence of creativity, 'entirely typical ... end product ... garden-variety' (p.362), can, provisionally at this stage, be regarded as characterizing the product of an automatic mechanical procedure. The analogy can then be refined to one between the extreme absence of creativity, rather than the not original as a whole, and computability.

My major concern here is then with elucidating the extreme absence of creativity in Feist, by a progressively developed argument. First, and primarily, the specific verbal and conceptual correlations indicated, between 'so mechanical' (Feist Publications, Inc. v. Rural Tel. Service Co., Inc., pp. 362-363) and an automatic mechanical procedure and from 'an age-old practice ... time-honored tradition' to what would naturally be regarded as computable, will be fully established, aiming at a degree of rigor proportionate to the significance of the correlation. Secondly, the sense of the other elements within the extreme absence of creativity, 'so ... routine' and 'entirely typical ... end product ... garden-variety' will be considered. Thirdly, the combination of all the clauses within the extreme absence of creativity will be addressed, in order to establish a clear and sufficient understanding of the complete absence of creativity, as embodied in a highly routine selection, coordination, or arrangement produced by an automatic mechanical procedure. Fourthly, the reading will be tested for its compatibility with the delineation of other elements of the not original, with insufficient creativity and the absence of independent creation. As the final part of the major concern, the strength of the proof and the value of the understanding of the absence of creativity established, including the possibility of determining it from compilations, will be considered. Some attention will then briefly be given to the implications of the argument for an understanding of insufficient creativity, a modicum of creativity, and originality.

\section{Correlation with a mechanical procedure}

The opening clause of the delineation of the not original in the opinion, 'so mechanical or routine', directly characterizes processes of selection, coordination, and arrangement which 'require no creativity whatsoever' (Feist Publications, Inc. v. Rural Tel. Service Co., Inc., 1991, p.362). '[S]o mechanical' is the first element of the clause and is then a highly, if not the most, significant characterization of processes without any creativity. It can be correlated with a mechanical procedure ${ }^{1}$, through specific similarities.

The most striking and immediate similarity subsists at the level of expression. '[M]echanical' in 'so mechanical' (Feist Publications, Inc. v. Rural Tel. Service Co., Inc., 1991, p.362) is the identical verbal form to mechanical in mechanical procedure, if both occurrences are considered as sequences of characters from the given alphabet and written language. In formal logic, a good notation or symbolism can reveal relations between ideas - 'Now we understand our feeling that we are in possession of the right logical conception, if only all is right in our symbolism' (Wittgenstein, 1922/1981, §4.1213). In this instance, the identity in expression is a similarity in itself and a compelling suggestion of further similarities. 
The common alphabet and language for mechanical are indicative of the contexts of use from which the term is derived. Mechanical in the opinion is not marked as a technical or specialized term by its alphabet or language, nor by citation, and is then best understood as taken from ordinary discourse. Similarly, mechanical in mechanical procedure was derived from ordinary English language discourse. Although logical and mathematical notation was subsequently used in making the concept of acting as a machine more precise, the ordinary discourse term is still retained. Both occurrences of mechanical are then derived from a relatively common context of use in ordinary discourse.

The common derivation from ordinary discourse has implications for the meaning of mechanical adopted by the opinion and for a mechanical procedure. Classically, it was asserted that, '[f]or a large class of cases - although not for all - in which we employ the word 'meaning' it can be defined thus: the meaning of a word is its use in the language' (Wittgenstein, 1953/1968, §43). The relative commonality of the context for derivation'the use in the language' - then implies some commonality in the meaning adopted. The particular context for derivation further implies that the ordinary discourse meaning was adopted both by the opinion and for a mechanical procedure.

The question then arises of whether the ordinary discourse meaning of mechanical adopted is retained. For its occurrence in the opinion, no departure from its ordinary discourse meaning can be found. For a mechanical procedure, the history of the development of the concept indicates that the ordinary discourse meaning of mechanical has been retained as an essential basis while precision has been added to the idea of acting as a machine (Herken, 1995). The ordinary discourse meaning of mechanical must then be understood as fully retained, for both occurrences.

The meaning of mechanical in ordinary discourse includes both a human acting mechanically and the operations of a machine. For the opinion, this dual application of mechanical can be supported by reference to a definition taken from a culturally and chronologically proximate monolingual dictionary, 'done as if by machine' (Grove et al., 1981), where the qualification, 'as if', can be read to indicate the inclusion of direct human activity. The concept of a mechanical procedure, from its preliminary scientific definition, embraces both a human acting mechanically and the operations of a machine, such as a computer.

The idea of acting mechanically implies an activity or process and this implication are realized in the opinion and for a mechanical procedure. '[S]o mechanical' in the opinion is contained within a paragraph introduced as concerned with 'selected, coordinated, or arranged' (Feist Publications, Inc. v. Rural Tel. Service Co., Inc., 1991, p.362) where the verb form indicates reference to an activity or process. It also, and more immediately, characterizes the 'selection and arrangement of facts', which can also be read to invoke processes (p.362). Procedure in mechanical procedure similarly refers to a type of process, from its definition ${ }^{2}$. '[S]o mechanical' (p.362) in the opinion and a mechanical procedure then have a further similarity in their reference to a process. 
Processes are invoked by denotation. '[S]o mechanical' (Feist Publications, Inc. v. Rural Tel. Service Co., Inc., 1991, p.362) in the opinion directly characterizes or denotes, rather than indirectly connotes, a type of process. A mechanical procedure also directly describes or denotes a process. Denotation is usually considered a stronger and more primary form than connotation (Eco, 1976, pp.55-86; Barthes, 1953/1984, pp.149-150). The strength of the connection to the processes invoked is then conveyed by denotation, for both the opinion and for a mechanical procedure. The common use of denotation also constitutes a significant similarity between 'so mechanical' in the opinion and mechanical in a mechanical procedure.

The most intense sense of mechanical is at issue in the opinion and for a mechanical procedure. So in 'so mechanical or routine' (Feist Publications, Inc. v. Rural Tel. Service Co., Inc., 1991, p.362) directly qualifies mechanical and indicates that it is to be understood in its most intense sense. Mechanical in a mechanical procedure is understood in an absolute sense, as matter of preliminary scientific definition, and this is occasionally marked by the additional term, automatic, in automatic mechanical procedure ${ }^{3}$. A similarity in intensity of meaning has then been established.

In summary, then, 'so mechanical' (Feist Publications, Inc. v. Rural Tel. Service Co., Inc., 1991, p.362) and an automatic mechanical procedure can be highly correlated with each other. They have an identity in their expression and strong similarities in the derivation of mechanical from ordinary discourse, the adoption and retention of its ordinary discourse meaning, the inclusion of directly human and of machine activity, the invocation of a process, and the use of denotation. The most intense sense of mechanical is at issue in the opinion and for a mechanical procedure. The identity and similarities approach exhaustivity in their inclusion of aspects of possible resemblance which could be considered significant for correlation. '[S]o mechanical' (p.362) in the opinion can then be definitively correlated with an automatic mechanical procedure (The correlations introduced and the interpretation made of the extreme absence of creativity are also graphically represented; see Figure 2).

The correlation, which rests on the initial gestalt effect of correspondence between the not original and understandings of computability, can itself serve as the immediate foundation for a further correlation, which links the historical in the opinion with the natural in understandings of computability.

\section{Correlation with computability as natural}

The sequence of clauses, from 'age-old practice' to 'time-honored tradition' (Feist Publications, Inc. v. Rural Tel. Service Co., Inc., 1991, p.363), constitutes the most connected and extensive delineation of processes completely lacking creativity in the opinion. The group of terms as whole has a historical resonance, although the particular term history is not used. The historical clauses in the opinion are separated from 'so mechanical' by 'routine' and by subsequent clauses, implying that they are indirectly connected to 'so mechanical'(Feist Publications, Inc. v. Rural Tel. Service Co., Inc., 1991, p.362) and may also relate to 'so ... routine'. In terms of the order of words within the 
absence of creativity in Feist and the computational process 9

\begin{tabular}{|c|c|c|c|c|c|c|c|c|}
\hline Delineation & $\begin{array}{l}\text { Degree of } \\
\text { absence of } \\
\text { creativity }\end{array}$ & $\begin{array}{l}\text { Process or } \\
\text { product }\end{array}$ & $\begin{array}{l}\text { Correlation } \\
\text { introduced }\end{array}$ & \begin{tabular}{|l} 
Correlations \\
as a whole
\end{tabular} & Routine & \begin{tabular}{|l} 
Extreme \\
absence of \\
creativity
\end{tabular} & $\begin{array}{l}\text { Other elements of } \\
\text { the not original }\end{array}$ & Not original \\
\hline so mechanical or routine & $\begin{array}{l}\text { as to require } \\
\text { no creativity } \\
\text { whatsoever }\end{array}$ & ||Process & $\begin{array}{l}\text { Automatic } \\
\text { mechanical } \\
\text { procedure }\end{array}$ & \multirow{5}{*}{$\begin{array}{l}\text { All relevant } \\
\text { elements in } \\
\text { the opinion } \\
\text { fully } \\
\text { correlated } \\
\text { with the } \\
\text { theory of } \\
\text { computability }\end{array}$} & & & & \multirow{5}{*}{$\begin{array}{l}\text { We conclude } \\
\text { that the } \\
\text { names, } \\
\text { towns, and } \\
\text { telephone } \\
\text { numbers } \\
\text { copied by } \\
\text { Feist were not } \\
\text { original to } \\
\text { Rural }\end{array}$} \\
\hline $\begin{array}{l}\text { entirely typical .... end product } \\
\ldots \text { garden-variety }\end{array}$ & $\begin{array}{l}\text { devoid of even } \\
\text { the slightest } \\
\text { trace of } \\
\text { creativity }\end{array}$ & |Product & & & \begin{tabular}{|l} 
A highly \\
routine \\
selection, \\
coordination, \\
or \\
arrangement. \\
\end{tabular} & A highly & & \\
\hline $\begin{array}{l}\text { 'selection' of a sort .... could } \\
\text { not be more obvious ... the } \\
\text { most basic information }\end{array}$ & $\begin{array}{l}\text { insufficient } \\
\text { creativity }\end{array}$ & $\begin{array}{l}\text { Process and } \\
\text { product }\end{array}$ & & & & $\begin{array}{l}\text { selection, } \\
\text { coordination, } \\
\text { or } \\
\text { arrangement } \\
\text { produced by }\end{array}$ & $\begin{array}{l}\text { The term, } \\
\text { information, is } \\
\text { consistent with the } \\
\text { computational } \\
\text { correlation. }\end{array}$ & \\
\hline $\begin{array}{l}\text { did not truly 'select' ... dictated } \\
\text { by state law }\end{array}$ & $\begin{array}{l}\text {... nothing } \\
\text { remotely } \\
\text { creative }\end{array}$ & $\mid$\begin{tabular}{|l} 
Process \\
(primarily) and \\
product \\
(secondarily).
\end{tabular} & & & & $\begin{array}{l}\text { an automatic } \\
\text { mechanical } \\
\text { procedure. }\end{array}$ & $\begin{array}{l}\text { Meaning reinforces } \\
\text { correlation with an } \\
\text { automatic } \\
\text { mechanical } \\
\text { procedure. }\end{array}$ & \\
\hline $\begin{array}{l}\text { an age-old practice, firmly } \\
\text { rooted in tradition and so } \\
\text { commonplace that it has come } \\
\text { to be expected as a matter of } \\
\text { course .... practically inevitable } \\
\text { time-honored tradition }\end{array}$ & $\mid \begin{array}{l}\text { nothing } \\
\text { remotely } \\
\text { creative }\end{array}$ & Process & $\begin{array}{l}\text { Naturally } \\
\text { regarded as } \\
\text { computable. }\end{array}$ & & & & & \\
\hline
\end{tabular}

Figure 2. Argument developed. 
opinion, 'routine' in 'so mechanical or routine' mediates between 'mechanical' and the historical. The mediation could be understood as revealing how mechanical processes can become routine as commonplace. The characterization of the process of alphabetical arrangement in the opinion in historical terms can be correlated with the understanding of computability in terms of the natural, with 'what would naturally be regarded as computable' (Turing, 1936-37/1993, p.249), through a number of similarities.

The primary similarity lies directly in meaning. The constituent substantive terms of the passage in the opinion - 'an age-old practice, firmly rooted in tradition and so commonplace that it has come to be expected as a matter of course ... practically inevitable ... time-honored tradition' (Feist Publications, Inc. v. Rural Tel. Service Co., Inc., 1991, p.363) — indicate long duration and transcendence of particular historical periods, approaching the natural. One clause, 'practically inevitable' (p.363), reveals the historical terminologically converging with the natural. Computability has been consistently conceived in terms of the natural, as what would naturally be regarded as computable ${ }^{4}$. The terms in the opinion and the natural in conceptions of computability are then similar to each other in their meaning.

The historical in the opinion and the natural in the concept of computability both invoke a set of processes conceived as objects for characterization. That a set of processes is at issue in the opinion is indicated by the gerund, or noun form of the verb, 'arranging' (Feist Publications, Inc. v. Rural Tel. Service Co., Inc., 1991, p.363). The natural in the concept of computability is also concerned with sets of processes conceived as objects for characterization. The common invocation of sets of processes conceived as objects for characterization constitutes a further similarity.

The mode of characterization of processes is indirect with elements of connotation. The historical reference and resonance of the clauses in the opinion functions as an indirect description of processes, in contrast to the direct denotation conveyed by 'so mechanical' (Feist Publications, Inc. v. Rural Tel. Service Co., Inc., 1991, pp.362-363). Denotation is beginning to move towards connotation. The conception of computability as natural which preexisted the formulation of satisfactory models of the computational process could be regarded as a concept or indirect description awaiting an object which fully corresponded to the conception. With the formulation and publication of models of the computational process, and their acceptance as absolute definitions, conceptions of computability as natural have tended to be reduced to connotations of a primary and more clearly articulated denotation. Both the clauses in the opinion and the natural in computability are, then, similar in functioning as indirect descriptions of processes, approaching connotation rather than denotation.

A contrast in meaning also emerges, directly between the historical resonance implied by the extensive chronological reference and references to 'tradition' in the opinion (Feist Publications, Inc. v. Rural Tel. Service Co., Inc., 1991, p.363) and the natural explicit in conceptions of computability. The contrast runs counter to the similarity established and could disturb the correlation being developed. 
The contrast's potential significance for disturbing the correlation can be reduced. The apparent sharpness of the difference immediately conveyed by the opposition of the historical to the natural is mollified when the long duration involved in the constituent terms of the opinion resonating with the historical is recalled. The independent status of the contrast is lessened by noting that the particular opposed elements are rooted in the underlying disciplinary bases from which different perspectives emerge. Law would have a humanistic and historical basis (Holmes, 1881/1991), corresponding to the historical resonance and reference of the terms in the opinion. Naturally regarded, and in its supporting role, intuitive, are resonant of a Platonist conception of mathematics, reflecting the disciplines from which the articulated concept of computability emerged. The disruptive potential of the contrast in meaning has then been reduced, by indicating its lack of sharpness and of independent status. A residual contrast between the historical and the natural remains.

In summary, then, the characterization of the antithesis to creativity in historical terms in the opinion can be correlated with the concept of computability, through a similarity in meaning, the common invocation of processes conceived as objects for characterization, and the indirect, approaching connotative rather than denotative, characterization of sets of processes. A contrast in meaning also emerged. The extensive similarities constitute a strong correlation between a significant component of the extreme antithesis to creativity in the opinion and the concept of computability, with a residual difference remaining within the encompassing correlation.

\section{Correlations as a whole}

Two correlations have been established, first and primarily, between 'so mechanical' (Feist Publications, Inc. v. Rural Tel. Service Co., Inc., 1991, p.362) and an automatic mechanical procedure, and, second and secondarily, the sequence of clauses with a historical resonance, 'age-old practice ... time-honored tradition' (p.363), with what would naturally be regarded as computable. Considering the correlations together can enhance the conviction to be attached to each correlation and to the correlations considered as a whole.

The correlation of the historical in the opinion with the natural in understandings of computability complements and by complementing reinforces the primary correlation of 'mechanical' with a mechanical procedure and of 'so mechanical' (Feist Publications, Inc. v. Rural Tel. Service Co., Inc., 1991, p.362) with an automatic mechanical procedure. The possibility of establishing a second correlation from the opinion to another central aspect of computability reinforces the sense that the theory of computation is an appropriate domain in which to seek correlations. '[M] echanical' (p.362) in the opinion can then be more definitively correlated with a mechanical procedure. Further, the theory of computability is primarily, although not necessarily exclusively, concerned with automatic procedures $^{5}$. The correlation of 'so mechanical' (p.362) with an automatic mechanical procedure is then strengthened. 
Considering the correlations as a whole also exposes parallels between the internal configuration of each body of thought. In the opinion, a direct description of type of process_-as 'so mechanical' (Feist Publications, Inc. v. Rural Tel. Service Co., Inc., 1991, p.362) - merges into a more indirect description of set of process conceived as objects for description, as 'an age-old practice ... time-honored tradition' (p.363), with denotation moving towards connotation. Analogously, the direct description or denotation of the computational process as a mechanical procedure is founded on a more indirect characterization of a set of processes, as what would naturally be regarded as computable ${ }^{6}$. Denotation of a type of process and indirect denotation moving towards connotation of a set of processes are, then, parallel between the opinion and understandings of the computational process and of computability (See Figure 3). The movements are thematically complementary although chronologically (understood as linear progression through a written text and as over historical time) reverse: in the opinion, the mechanical merges into the historical through the routine; for the theory of computability, historically established and routine procedures of calculation are rendered mechanical. The structural parallelism adds conviction to each of the separately established correlations and to the correlations considered as a whole.

The correlations considered together are comprehensive with regard to each correlated body of thought. '[S]o mechanical' itself and all the elements in the opinion which amplify it, from the specific individual words and their legitimately attributable senses, through the relations between words within clauses, and then to relations between clauses (Feist Publications, Inc. v. Rural Tel. Service Co., Inc., 1991, pp.362-363), have been included as elements for linking. Centrally significant elements of understandings of the computational process and of computability are similarly all included, at the level of concepts - of an automatic mechanical procedure or algorithm and of computabilityalthough still including specific verbal formulations whose recurrence is indicative of their significance, 'naturally regarded as computable' (Turing, 1936-37/2004, p.249). The comprehensiveness of inclusion and linking can be graphically confirmed, for words and clauses within the opinion, their connection to one another, and their correlations with understandings of the computational process and of computability (See Figure 3). The comprehensiveness of the correlations indicates that the two bodies of thought have been fully matched.

On the basis of the more definitive correlation of 'so mechanical' (Feist Publications, Inc. v. Rural Tel. Service Co., Inc., 1991, p.362) with an automatic mechanical procedure, the enhanced conviction obtained from the parallelism revealed, and the comprehensive linking of the two bodies of thought, the separately established correlations can be fully combined. '[S]o mechanical' (Feist Publications, Inc. v. Rural Tel. Service Co., Inc., 1991, p.362) and all its amplifying terms in the opinion are then entirely correlated with the theory of computability in its strictest or purest sense where it is concerned with automatic mechanical procedures. 


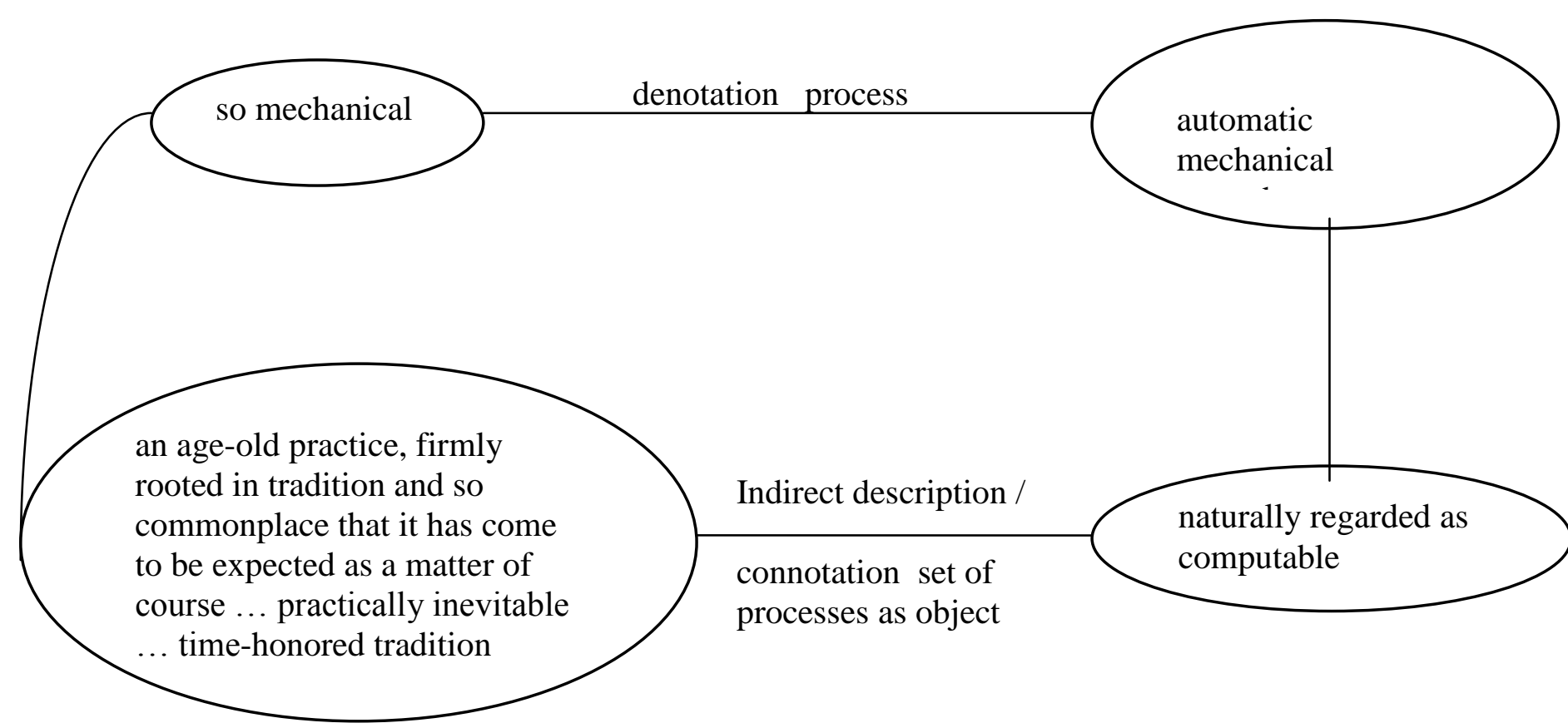

Figure 3. Correlation between the opinion and computability 


\section{The routine in the extreme absence of creativity}

The argument has still to account for the elements in the opinion which contribute to the characterization of 'so ... routine' and its amplifying components, 'entirely typical ... end product ... garden-variety' (Feist Publications, Inc. v. Rural Tel. Service Co., Inc., 1991, p.362).

'[R]outine' (Feist Publications, Inc. v. Rural Tel. Service Co., Inc., 1991, p.362) must be understood in its central ordinary discourse sense. It is indirectly qualified by the intensifier, 'so', and can then be received in a relatively intense sense. ' $[\mathrm{S}] \mathrm{o} . .$. routine' (p.362) qualifies processes of selection, coordination, and arrangement.

It is amplified by two mutually proximate clauses within the extreme absence of creativity, 'Rural's white pages are entirely typical', and, '[t]he end product is a garden-variety white pages directory' (Feist Publications, Inc. v. Rural Tel. Service Co., Inc., 1991, p.362). '[T]ypical', and 'garden-variety' (p.362) are also understandable in their central ordinary discourse senses. '[T]ypical' is directly qualified by 'entirely', and 'garden-variety' semantically contains a degree of intensity. The collective result is, then, a stronger or more intense sense of routine than that conveyed by 'so ... routine' (p.362) itself. The contemporary reference of the clauses considered as a whole is exposed by its contrast with the historical resonance of the final sequence of clauses, 'an age-old practice, firmly rooted in tradition ... time-honored tradition', with their repetition of 'tradition'. (Feist Publications, Inc. v. Rural Tel. Service Co., Inc., 1991, pp.362-363). In contrast to 'so ... routine', 'entirely typical' and 'garden-variety' (p.362) directly qualify a product and the term, 'end product' (p.362), understandable as the outcome of a process, is itself used.

In summary, then, 'so ... routine' and its directly amplifying terms, 'entirely typical' and 'garden-variety' within the extreme absence of creativity (Feist Publications, Inc. v. Rural Tel. Service Co., Inc., 1991, p.362) should be understood in their central ordinary discourse senses. '[E]ntirely typical' and garden-variety' convey a stronger sense of routine than 'so ... routine' (p.362) itself and are explicitly marked as qualifying a product rather than process. The clauses as a whole have a contemporary reference.

\section{The extreme absence of creativity}

It is the clauses collectively - 'so mechanical or routine', 'entirely typical ... gardenvariety', and 'an age-old practice, firmly rooted in tradition and so commonplace that it has come to be expected as a matter of course ... practically inevitable ... time-honored tradition' (Feist Publications, Inc. v. Rural Tel. Service Co., Inc., pp. 362-363) - and not individually, which fully occupy the extreme absence of creativity. The question then arises of the relation between the 'so mechanical' and 'so ... routine' (p.362), and their amplifying clauses, within the extreme absence of creativity.

The constituent substantive terms, 'mechanical' and 'routine', of the opening and dominant clause, 'so mechanical or routine', are closely proximate to each other in terms

of the order of words in the opinion and are both qualified by 'so' (Feist Publications, Inc. 
v. Rural Tel. Service Co., Inc., p.362), although directly and indirectly. In the subsequent development of the delineation of the absence of creativity, the mechanical does not enter into significant contradiction with the routine but is rather mediated or connected to the historical by the routine. The clauses with a historical resonance also have a semantic affinity with 'so ... routine' (p.362) and its amplifying elements. A close association, but not a high similarity or identity, can then be read as the relation between 'so mechanical' and 'so ... routine' (p.362), with priority conferred on mechanical by its initial position and direct intensifying qualifier.

The relation can be translated into more formally logical terms to enhance definiteness and clarity. The linking of relatively semantically distinct, although not contradictory, terms by 'or' in 'so mechanical or routine' emerges as an unusual, although not a dissonant use of $o r$, when compared to its dominant use in modern written English and within the opinion. It can still be read as logical OR, which would have been the customary translation if the terms were highly overlapping in meaning, but with the expectation that the conjunction, or AND, which is contained in inclusive OR, will be substantially and significantly occupied. The reading holds, in strictly logical terms, whether we associate the terms with a historical resonance, understood to be connected to one another by OR, exclusively with 'so mechanical' (p.362) or allow them to be distributed between the 'so mechanical' and the 'so ... routine' (p.362). '[S]o mechanical or routine' (p.362) directly qualifies a process and the connected sequence of terms with a historical resonance are also concerned with processes. We can then read the primary relation between 'so mechanical' and 'so ... routine' (p.362) as so mechanical OR so ... routine, with both mechanical and routine understood to qualify processes.

The relation of 'so mechanical or routine' to the other elements within the extreme absence of creativity has next to be considered. Although 'so ... routine' itself directly qualifies a type of process, the terms which amplify the routine within the extreme absence of creativity refer directly and explicitly to products, 'entirely typical ... end product ... garden-variety’ (Feist Publications, Inc. v. Rural Tel. Service Co., Inc., pp.362-363). Almost tautologically, a product is the result of a process, with the relation here captured by the term, 'end product' [emphasis added] (p.363). The relation can then be understood as a 'so mechanical or routine' process which gives rise to an 'entirely typical or 'gardenvariety' 'end product' (p.363), or as 'so mechanical or routine' AND 'entirely typical ... garden-variety'. The logical formulation is consistent with the primary OR relation between the 'so mechanical' and the 'so ... routine' (p.362), but restricted to the conjunction, which the semantic tension between the two dominant and initial terms had led us to expected to be substantially and significantly occupied.

The overall relation can be rendered logically as, (so mechanical OR so ... routine process) AND (entirely typical OR garden-variety product). Both 'so mechanical' (p.362) itself and the sequence of clauses with a historical resonance, from 'an age-old practice' to 'timehonored tradition' (p.363), have been correlated with the concept of computability and specifically with an automatic mechanical procedure. We can then substitute the correlation established, as an (automatic mechanical procedure OR so ... routine process) AND (entirely typical OR garden-variety product). A purely verbal formulation, 
equivalent to the logical formulation, can also be given: The extreme absence of creativity can be understood as manifested in a highly routine, entirely typical or garden-variety, selection, coordination, and arrangement produced by an automatic mechanical procedure or routine process.

The different combinations of terms which meet the logical requirements for the extreme absence of creativity can be considered in order to determine the relative significance of 'so mechanical' and 'so ... routine' (Feist Publications, Inc. v. Rural Tel. Service Co., Inc., p.362).

- A process which is both 'so mechanical' and 'so ... routine' (p.362) gives rise to the strongest form of the extreme absence of creativity, when combined with a highly routine product.

- A 'so mechanical' (p.362) process which gives rise to a highly routine product would still very strongly qualify, given the priority attached to 'so mechanical' (p.362).

- A 'so ... routine' (p.362) process combined with a highly routine product would also qualify logically, although not as strongly. The category is empirically unlikely to be substantially populated by instances of compilations: if a 'so ... routine' process is potentially an automatic mechanical procedure, it may well be rendered such to reduce immediate costs.

'[S]o mechanical', then, emerges as the primary differentiating element, while 'so ... routine' is of limited independent significance.

The significance of 'so ... routine' (Feist Publications, Inc. v. Rural Tel. Service Co., Inc., p.362) as it qualifies processes can be further clarified. From a logical perspective, 'entirely typical' and 'garden-variety' (p.363) can be understood as species of the 'so ... routine', or as highly routine. '[S]o ... routine' qualifying a process is then beginning to appear tautological, in the sense that the conjoined terms, "entirely typical ... gardenvariety' (p.362), are subsets of 'so ... routine' (p.32). More empirically, and allowing the substitution of an automatic mechanical procedure for 'so mechanical' (p.362), a 'so mechanical' process or automatic mechanical procedure would normally give rise to a highly routine product, strongly meeting the conditions of the overall logical statement for the extreme absence of creativity, before the process itself becomes 'so ... routine' (p.362) through diffusion over time. '[S]o ... routine' (p.362) as it qualifies a process can, then, be considered of limited differentiating significance, from both logical and empirical considerations.

All instances of compilations which are highly routine selection, coordination, and arrangements would fall under all of the three expressions which were analytically gathered together under the extreme absence of creativity. For processes, 'so mechanical or routine' is linked to 'no creativity whatsoever' and 'an age-old practice ... time-honored tradition' to 'nothing remotely creative' (Feist Publications, Inc. v. Rural Tel. Service Co., Inc., pp.362-363). For products, 'entirely typical ... garden-variety' are directly characterized as 'devoid of even the slightest trace of creativity' (p.362). The triple invocation confirms the strength of the delineation of the extreme absence of creativity and its status as an analytic overlay, helpful but not essential to the argument. 
We have then obtained a clear and sufficient understanding of the extreme absence of creativity, amenable to clear and concise expression. The understanding is sufficiently precise and significant to warrant isolation and emphasis.

The extreme absence of creativity is manifested in a highly routine, entirely typical or garden-variety, selection, coordination, and arrangement produced by an automatic mechanical procedure or routine process.

A complex argument has arrived at a simple conclusion, which absorbs all elements of the extreme absence of creativity.

\section{Other elements of the not original}

The extreme absence of creativity is highly significant to the not original, and determines its presence, but does not fully occupy it. The not original also contains 'insufficient creativity' (Feist Publications, Inc. v. Rural Tel. Service Co., Inc., 1991, pp.362-363) and the absence of independent creation (p.363). The validity of the understanding established of the extreme absence of creativity can be tested by examining the extent of its compatibility with the other elements of the not original.

The term, information, occurs in the delineation of products which embody 'insufficient creativity' in the clause, 'the most basic information' (Feist Publications, Inc. v. Rural Tel. Service Co., Inc., 1991, pp.362-363). '[I]nformation' (p.362), in its occurrence in this passage, can be understood as conforming with the use of 'information' elsewhere in the opinion where it is consistently used in differentiation from data, most intensely from 'raw data' (p.361), as data organized into a more coherent form. The sense legitimately attributable to the particular use of 'information' (p.363) is then both consistent with and reminiscent of fully articulated and widely diffused understandings developed from computational contexts, where information is regarded as data organized to some purpose (Blair, 2002, pp.1019-1020). The reminiscence of computational contexts then reinforces the appropriateness of theory of computability as a resource for significant correlations.

The delineation of the absence of independent creation includes the final summative clause, 'dictated by state law' (Feist Publications, Inc. v. Rural Tel. Service Co., Inc., 1991, p.363). The particular manifestation of the absence of independent creation in the not original has already been revealed to be connected with the extreme absence of creativity, with 'nothing remotely creative' (p.363). The meaning of 'dictated by state law' (p.363), particularly its connotative meaning, as distinct from the reference of the paragraph which it concludes, can be read to support the interpretation of the extreme absence of creativity established.

'[D]ictated' (p.363) as a verb invokes a process rather than the product of selection, indicated by the verb form select in 'did not truly 'select' (p.363). Law (p.363) refers to a law or very strong rule imposed on a process from outside that process. 'Dictated ... by law' (p.363) can then be understood as be understood as an intense form of specification, 
with intensity semantically contained within the primary term, dictated, rather than added by a qualifier. An intense form of specification by an external law is reminiscent of popular understandings of the automatic computational process and consistent with the understanding of the computational process within the theory of computability. The meaning of 'dictated by ... law' (p.363) then reinforces the correlation of 'so mechanical' (p.362) with an automatic mechanical procedure. '[S]tate' in 'state law' (p.363) can be understood as an exemplification of the routine and as qualifying primarily the process and secondarily the product of selection. '[D]ictated by ... law' (p.363) and 'state' (p.363) are integral parts of a single clause and can then be read as a conjunction.

The meaning of 'dictated by state law' is then consistent with the interpretation developed of the extreme absence of creativity, as so mechanical OR so ... routine with the expectation that the conjunction, or AND, will be substantially and significantly occupied. Applying to Rural's white pages as an exemplar, it also illustrates the most inclusive logical reading (a so mechanical AND so ... routine process AND a highly routine product) identified as possibly the strongest form of the extreme absence of creativity. The meaning of 'dictated by state law' (p.363) then supports the correlation with an automatic mechanical procedure, the interpretation of the extreme absence of creativity established, and the identification of the most inclusive logical reading as the strongest form of the extreme absence of creativity (the meaning, although not the reference, of 'dictated by state law' can also be represented by a dark overlay; see Figure 2).

In summary, then, the appropriateness of the theory of computability for correlations of elements from the opinion was supported by the further elements of consistency between the opinion and broader contexts associated with computation, captured in the term information. '[S]o mechanical' can also be further and more strongly correlated with an automatic mechanical procedure, from the meaning of 'dictated by ... law' (p.362). The interpretation established of the extreme absence of creativity is, then, not only compatible with the delineation of the other elements of the not original but is positively supported by a reading of them.

\section{Existence and value of the understanding of the absence of creativity}

The strength of the existence of the reading established of the delineation of the extreme absence of creativity in the opinion can be considered, by reference to the qualities of the argument. The initial gestalt effect of an analogy between the not original in Feist and classic and continuing understandings of computability has been strengthened and also refined, by identifying and making fully explicit the correspondences informing but subsumed in the initial gestalt. A significant analytic gain over the overall analogy has been obtained, particularly in the distinction of the extreme absence of creativity from the other elements of the not original. The other elements of the not original, insufficient creativity and the absence of independent creation, supported the reading obtained. A gestalt effect is, by definition, not necessarily subjectable to decomposition without loss of conviction. Decomposition, and then recomposition, with enhanced conviction and with analytic gain then confirm the strength of the initial gestalt. The argument has also had a degree of exhaustivity with regard to the relevant bodies of thought analogous to the 
requirement that 'a court should give effect, if possible, to every clause and word of a statute' (Feist Publications, Inc. v. Rural Tel. Service Co., Inc., 1991, p.358). All significant words, clauses, and distinctions for the opinion and significant expressions, particularly mechanical procedure, and concepts for the more extensive literature of computability have been mutually correlated. The demonstration of the analogy and its constituent correlations, and the combination of the correlated elements with the highly routine in the opinion, amounts to as strong a proof as can be reasonably expected or demanded outside of logical and mathematical domains, where further propositions can be tautologically generated from axioms (Wittgenstein, 1922/1981). The existence of the reading has then been proven, beyond reasonable doubt.

The value, as distinct from the existence, of the reading continues to emerge from the rendering of the extreme absence of creativity into something capable of being known. Two conditions can distinguished.

- First, where the processes of selection, coordination, and arrangement of the work in which property is claimed are definitively known from observation, reliable testimony, or evidence of those processes, and the product is open to inspection (the product must be fixed for property to be claimed and can then assumed to be generally available).

- Secondly, where the process is not directly knowable and the product remains available.

Possibilities for knowledge of the process vary across these conditions while those for the product are relatively invariant.

The first condition, where processes are known, can be considered.

- Processes would be identified as 'so mechanical' (Feist Publications, Inc. v. Rural Tel. Service Co., Inc., 1991, p.362) when they correspond to an automatic mechanical procedure, either conducted by a computer as machine or by a human acting mechanically, and this can be definitively determined.

- The extent to which the processes are 'so ... routine ... an age-old practice, firmly rooted in tradition and so commonplace that it has come to be expected as a matter of course ... practically inevitable ... time-honored tradition' (Feist Publications, Inc. v. Rural Tel. Service Co., Inc., 1991, pp.363-363) can be assessed by comparison with other processes widely recognized as such and the process of determination may not give rise to as sharp a boundary. However, if the processes are also identified as 'so mechanical' (p.362) the conditions for the extreme absence of creativity in processes have then been strongly met and if the processes are not 'so mechanical' fulfilling the conditions for being highly routine is empirically unlikely.

- Whether the product in which property is claimed is highly routine can be more directly determined, by comparison with other 'end product[s]' already understood as highly routine or 'entirely typical ...garden-variety' (p.362).

Where processes are known, then, determination of the extreme absence of creativity should be readily possible, strongly with regard to whether processes are 'so mechanical' (p.362), slightly less definitively with regard to their being 'so ... routine' (p.362), but 
with limited implications for the determination of the absence of creativity, and reasonably confidently as to whether the product is highly routine.

Under the second condition, where processes are not definitively known, whether they were 'so mechanical or routine' (Feist Publications, Inc. v. Rural Tel. Service Co., Inc., 1991, p.363) can then only be determined from their congealed presence in the product.

- The possibilities for determining the primary differentiating element, of 'so mechanical' (p.362), can be considered from a triple perspective. First, the indirect deduction of the absence of creativity from a product is an extension of established modes of determining copying for the purposes of copyright - 'it is generally not possible to establish copying as a factual matter by direct evidence' (Nimmer \& Nimmer, 1978/2009, 13.01[b]) — with reference to the work in which property is claimed rather than the possibly copied product. The detection of copying for the purposes of copyright has not proved problematic. Determination of a 'so mechanical' (p.362) process from a product is then an extension, possibly even a special case, of a well-established and confidently trusted procedure in copyright practice. It should then be possible to assimilate it to copyright practice. Secondly, reading processes of construction from the product is consistent with the ordinary discourse sense of mechanical, as 'done as if by machine' (Grove et al., 1981), which directly invokes a process but implies the possibility of reading the type of process from the product. The presence of this sense in ordinary discourse is indicative of the commonplace nature of the form of reading indicated. Thirdly, with regard to the computational context, recourse can be made to understandings, classically regarded intuitive, of what is naturally computable. These established understandings are currently being extensively supplemented by historically and experientially acquired understandings being developed from the wide diffusion of instances of automatic mechanical procedures into everyday life, including the construction of compilations. The possibility of constructing mechanical procedures which would give rise to similar results, broadly reverse engineering, could also be considered. An indication of a high level of certainty in identifying those processes which are 'so mechanical' (p.362) has, then, been obtained.

- The extent to which processes meet the conditions for being 'so ... routine' (p.362) and historically established practices can be inferred through comparison with products of other processes already recognized as highly routine. The extent to which processes are routine remains not crucial to strongly establishing the extreme absence of creativity.

- Whether products are highly routine can continue to be determined by comparison with other contemporary products.

The extreme absence of creativity can, then, be confidently identified in its crucial aspects of a 'so mechanical' (p.362) process and a highly routine product, where processes are not initially definitively known.

Procedures for the determining whether a compilation embodies the extreme absence of creativity, promise to be simple, robust, and intelligible, in accord with the established practices of the field, and implementable under distinguishable conditions, effectively constituting a judicially applicable test. A high degree of value has then been established 
for a reading whose existence was strongly proven (The conclusions of the argument are also graphically represented; see Figure 4).

The reading of the extreme absence of creativity would have further value if it could also account for the other distinctive element of the not original, insufficient creativity, and for the original, constituted by a modicum of creativity and independent creation. The extreme absence of creativity would then be fully given the pivotal role its position in the text of the decision implies it should have. These issues can be briefly anticipated, as implications.

\section{Implications}

We are now concerned not with the compatibility between the interpretation established of the extreme absence of creativity and the other elements of the not original, or the original itself, but with identifying the crucial elements of difference. Creativity is the underlying and common concept involved in insufficient creation, a modicum of creativity, and independent creation but is not greatly delineated in the opinion. From the reading established here, it can be understood as the antithesis or negation of the extreme absence of creativity, as embodied in a not highly routine product of processes which are neither 'so mechanical' (Feist Publications, Inc. v. Rural Tel. Service Co., Inc., 1991, p.362-363), or an automatic mechanical procedure, nor 'so ... routine' (p.362). '[I]nsufficient creativity' is delineated in the opinion as a process which 'could not be more obvious' which results in the 'most basic information' (p.362). '[C]ould not be more obvious' can include, but need not be limited to, an automatic mechanical procedure and the 'most basic information' can be understood as still a routine, but not so highly routine, product. The delineation of insufficient creativity is therefore consistent with, and supports, the more logically derived interpretation of creativity as the antithesis to the absence of creativity. A modicum of creativity is not significantly directly delineated in the opinion but is understood as definitely embodied in a product, the 'precise words' (p.348) of a written publication, which would exceed the 'most basic information' (p.362), and is also consistent with the logically derived understanding of creativity. Full, as distinct from technical, independent, creation requires a modicum of creativity but is more directly relevant to who created and therefore owns the property in a work. Together, a modicum of creativity and independent creation constitute the original. All the other significant concepts in the opinion can, then, be understood on the basis of treating creativity as the antithesis to or negation of the interpretation established of the extreme absence of creativity. 
absence of creativity in Feist and the computational process 22

\begin{tabular}{|c|c|c|c|c|c|c|c|}
\hline Not original & $\mid \begin{array}{l}\text { Constituent } \\
\text { concept of the } \\
\text { not original }\end{array}$ & $\begin{array}{l}\text { Corresponding clauses } \\
\text { within the not original }\end{array}$ & Delineation & \begin{tabular}{|l} 
Degree of \\
absence of \\
creativity
\end{tabular} & \begin{tabular}{|l} 
Correlation introduced \\
or interpretation made
\end{tabular} & \begin{tabular}{|l} 
Extreme \\
absence of \\
creativity
\end{tabular} & Not original \\
\hline \multirow{5}{*}{$\begin{array}{l}\text { The question that } \\
\text { remains is } \\
\text { whether Rural } \\
\text { selected, } \\
\text { coordinated, or } \\
\text { arranged these } \\
\text { uncopyrightable } \\
\text { facts in an } \\
\text { original way }\end{array}$} & \multirow{3}{*}{$\left|\begin{array}{l}\text { Not } \\
\text { possessing } \\
\text { some minimal } \\
\text { degree of } \\
\text { creativity }\end{array}\right|$} & $\begin{array}{l}\text { the Constitution } \\
\text { mandates some minimal } \\
\text { degree of creativity }\end{array}$ & so mechanical or routine & \begin{tabular}{|l} 
as to require no \\
creativity \\
whatsoever
\end{tabular} & $\begin{array}{l}\text { Automatic } \\
\text { mechanical procedure }\end{array}$ & \multirow{5}{*}{$\begin{array}{l}\text { The extreme } \\
\text { absence of } \\
\text { creativity is } \\
\text { manifested in } \\
\text { a highly } \\
\text { routine } \\
\text { selection, } \\
\text { coordination, } \\
\text { and } \\
\text { arrangement } \\
\text { produced by } \\
\text { an automatic } \\
\text { mechanical }\end{array}$} & \multirow{5}{*}{$\begin{array}{l}\text { We conclude } \\
\text { that the names, } \\
\text { towns, and } \\
\text { telephone } \\
\text { numbers copied } \\
\text { by Feist were } \\
\text { not original to } \\
\text { Rural }\end{array}$} \\
\hline & & \begin{tabular}{|l|} 
do not satisfy the \\
minimum constitutional \\
standards for copyright \\
protection
\end{tabular} & $\begin{array}{l}\text { entirely typical ... end product } \\
\ldots \text { garden-variety }\end{array}$ & \begin{tabular}{|l} 
devoid of even \\
the slightest \\
trace of creativity
\end{tabular} & $\begin{array}{l}\text { A routine selection, } \\
\text { coordination, or } \\
\text { arrangement. }\end{array}$ & & \\
\hline & & $\begin{array}{l}\text { lacks the modicum of } \\
\text { creativity necessary [for] } \\
\text { copyrightable } \\
\text { expression }\end{array}$ & $\begin{array}{l}\text { 'selection' of a sort .... could } \\
\text { not be more obvious ... the } \\
\text { most basic information }\end{array}$ & $\begin{array}{l}\text { insufficient } \\
\text { creativity }\end{array}$ & \begin{tabular}{|l} 
The term, information, \\
is consistent with the \\
computational \\
correlation.
\end{tabular} & & \\
\hline & \begin{tabular}{|l|} 
Not \\
independently \\
created by the \\
author.
\end{tabular} & $\begin{array}{l}\text { may also fail the } \\
\text { originality requirement } \\
\text { for another reason }\end{array}$ & $\begin{array}{l}\text { did not truly 'select' ... dictated } \\
\text { by state law }\end{array}$ & \begin{tabular}{|l}
... nothing \\
remotely creative
\end{tabular} & \begin{tabular}{|l|} 
Meaning reinforces \\
correlation with an \\
automatic mechanical \\
procedure.
\end{tabular} & & \\
\hline & $\mid \begin{array}{l}\text { Not } \\
\text { possessing } \\
\text { some minimal } \\
\text { degree of } \\
\text { creativity }\end{array}$ & $\begin{array}{l}\text { does not possess the } \\
\text { minimal creative spark } \\
\text { required by the } \\
\text { Copyright Act and the } \\
\text { Constitution }\end{array}$ & $\begin{array}{l}\text { an age-old practice, firmly } \\
\text { rooted in tradition and so } \\
\text { commonplace that it has come } \\
\text { to be expected as a matter of } \\
\text { course ... practically inevitable } \\
\text {... time-honored tradition }\end{array}$ & $\begin{array}{l}\text { nothing remotely } \\
\text { creative }\end{array}$ & $\begin{array}{l}\text { Naturally regarded as } \\
\text { computable. }\end{array}$ & & \\
\hline
\end{tabular}

Figure 4. Summary of conclusions. 


\section{Conclusion}

The extreme absence of, or antithesis to, creativity has, then, been precisely identified, primarily through a careful and exhaustive process of correlation. A precise correlation, of 'so mechanical' and its amplifying elements (Feist Publications, Inc. v. Rural Tel. Service Co., Inc., 1991, pp.362-363) with an automatic mechanical procedure, has been established which strengthens and refines the gestalt effect of analogy between the not original and computability. The identification of the extreme absence of creativity as manifested in a highly routine selection, coordination, and arrangement produced by an automatic mechanical procedure was consistent with the characterization of the other elements of the not original, insufficient creativity and the absence of independent creation. The extreme absence of creativity can be given, in accord with its position within the opinion, a pivotal role in elucidating other significant concepts in the opinion. The understanding of the extreme absence of creativity and its role in the not original constitutes a considerable, and potentially highly valuable, elucidation of a previously complex, variously and poorly understood, categories. The identification of the extreme absence of creativity fulfils a rigorous test for knowledge, as 'an ideal reproduction of the external world serviceable for cooperative action thereon' (Childe, 1956, p.54). The potential for cooperative action emerges, at this stage of the development of the argument, primarily from the correlation of the extreme absence of creativity with something capable of being known, and, secondarily and by implication, from the understanding obtained of creativity and originality. 


\section{References}

Barthes, R. (1953/984). Elements of semiology. In R. Barthes. Writing degree zero \& Elements of semiology. Translated by A. Lavers and C. Smith. London: Jonathan Cape.

Blair, D.C. (2002). Knowledge management: Hype, hope, or help? Journal of the American Society for Information Science and Technology. 53, 1019-1028.

Boolos, G.S. and Jeffrey, R.C. (1989). Computability and logic. 3rd edition. Cambridge, England and New York, etc.: Cambridge University Press.

Childe, V.G. (1956). Society and knowledge. London: George Allen \& Unwin.

Church, A. (1936/2004). An unsolvable problem of elementary number theory. In M. Davis (Ed.). The undecidable: basic papers on undecidable propositions, unsolvable problems and computable functions (pp.89-107). Mineola, New York: Dover Publications.

Davis, M. (1982). Computability \& unsolvability. New York: Dover Publications.

Davis, M. (1995). Mathematical logic and the origin of modern computing. In R. Herken (Ed.). The universal Turing machine: a half-century survey (pp.149-174). Oxford etc.: Oxford University Press.

Davis, M. (2000). The universal computer: the road from Leibniz to Turing. New York, W.W. Norton.

Davis, M. (Ed.). (2004). The undecidable: basic papers on undecidable propositions, unsolvable problems and computable functions. Mineola, New York: Dover Publications.

Eco, U. (1976). A theory of semiotics. London and Bloomington: Indiana University Press.

Feist. (1991). Feist Publications, Inc. v. Rural Tel. Service Co., Inc. 499 U.S. 340.

Gödel, K. (1946/2004). Remarks before the Princeton bicentennial conference on problems in mathematics. Address given in 1946. In M. Davis (Ed.). The undecidable: basic papers on undecidable propositions, unsolvable problems and computable functions (pp.84-88). Hewlett, N.Y.: Raven Press.

Gödel, K. (1964/2004). Postscriptum [To, On undecidable propositions of formal mathematical systems]. In M. Davis (Ed.). The undecidable: basic papers on undecidable propositions, unsolvable problems and computable functions (pp.71-73). Hewlett, N.Y.: Raven Press.

Goldstein, P. (1991). Copyright. Journal, Copyright Society of the U.S.A.. pp.109-122. 
Grove, P.B. et al. (Eds.). (1981). Webster's third new international dictionary of the English language, unabridged. Springfield, MA: G. \&C. Merriam Co.

Herken, R. (Ed.). (1995). The universal Turing machine: A Half-Century Survey. $2^{\text {nd }}$ edition. New York and Vien: Springer-Verlag.

Holmes, O.W. (1881/1991). The common law. With a new introduction by Sheldon M. Novick. New York: Dover Publications, 1991. First published 1881.

Minsky, M.L. (1967). Computation: finite and infinite machines. Englewood Cliffs, NJ: Prentice-Hall.

Narayanan, A.S. (1993-1994). Standards of protection for databases in the European Community and the United States: Feist and the myth of creative originality. George Washington journal of international law and economics, 27, 457-500.

Nimmer, M.B. and Nimmer, D. (1978-2009). Nimmer on copyright: a treatise on the law of literary, musical and artistic property, and the protection of ideas. New York: Matthew Bender, 1978- updated to December 2009.

Post, E.L. (1936/2004). Finite combinatory processes. Formulation 1. In M. Davis (Ed.). The undecidable: basic papers on undecidable propositions, unsolvable problems and computable functions (pp.289-291). Mineola, New York: Dover Publications.

Turing, A.M. (1936-1937/2004). On computable numbers, with an application to the Entscheidungsproblem. (Paper read 12 November 1936). In M. Davis (Ed.). The undecidable: basic papers on undecidable propositions, unsolvable problems and computable functions (pp.116-151). Mineola, New York: Dover Publications.

Turing, A.M. (1939/2004). Systems of logic based on ordinals. In M. Davis (Ed.). The undecidable: basic papers on undecidable propositions, unsolvable problems and computable functions (pp.155-222). Mineola, New York: Dover Publications. First published Proceedings of the London Mathematical Society. Series 2. 45, 1939, pp.161228.

Warner, J. (2010). So mechanical or routine: the not original in Feist. Journal of the American Society for Information Science and Technology. 61, 820-834.

Wilks, Y.A., Slator, B.M., and Guthrie, L.M. (1996). Electric words: dictionaries, computers, and meanings. Cambridge, MA: The MIT Press.

Wittgenstein, L. (1922/1981). Tractatus Logico-Philosophicus. London and New York: Routledge and Kegan Paul.

Wittgenstein, L. (1953/1968). Philosophical investigations. Oxford: Basil Blackwell. 
1 The relation of the scope of the term, mechanical procedure, to that of other terms, such as algorithm and effective procedure, can be summarily indicated.

The computational process was classically characterized in mechanical terms. The concept and term, mechanical procedure, emerged from a model of a human computer acting mechanically.

We may compare a man in the process of computing a real number to a machine which is only capable of a finite number of conditions (Turing, 1936-37/2004, p.117).

A mechanical procedure then corresponds to a computational process and includes a human acting mechanically or as a machine.

The model of the computational process with which the term mechanical procedure is associated was intended to encompass pre-existing terms and concepts, including algorithm, but to give them a more precise and materially definite form. The equivalence of the model developed by Turing to pre-existing concepts was rapidly accepted and became a grounding assumption for computer science:

Turing's work gives an analysis of the concept of 'mechanical procedure' (alias 'algorithm' or 'computation procedure' or 'finite combinatorial procedure'). This concept is shown to be equivalent with that of a 'Turing machine'.' (Gödel, 1964/2004, p.72)

The equivalence in scope of processes covered does not necessarily imply full synonymy between constituent terms, in the sense of complete inter-substitutability in different written or spoken sequences, and some writers have expressed careful reservations.

We will use the latter term [effective procedure] in the sequel. The terms [algorithm and effective procedure] are roughly synonymous, but there are a number of different shades of meaning used in different contexts, especially for 'algorithm'. (Minsky, 1967, p.105n)

The term, mechanical procedure, is not used by Minsky and is not, then, immediately covered by the reservation indicated. Even given the reservation, an algorithm and effective procedure are not differentiated in terms of the scope of procedures covered from the Turing machine model to which Gödel refers and are still regarded as 'roughly synonymous' (Minsky, 1967, p.105n). The scope of computational processes covered by mechanical procedure, algorithm, and effective procedure can be considered coterminous, for the analytical purposes here.

The term, mechanical procedure, will be the preferred, although the not the exclusive, term here, for its classical origins, precise description, and the direct verbal connection it offers with the opinion.

${ }^{2}$ Mechanical procedure refers immediately to a process rather than a product. The term, 'process', was itself used in early expositions (Turing, 1936-37/2004)). The specific expression, '(mechanical) process' [punctuation from original], was used in the paper formulating the model (Turing, 1936-37/2004, p.148) with extensive references to, 'general process' (Turing, 1936-37/2004), for instance:

The expression "there is a general process for determining ... has been used throughout this section as equivalent to 'there is a machine which will determine ...' (Turing, 1936-37/2004, p.134).

A mechanical procedure can then definitively be regarded as a form of process.

3 An automatic mechanical procedure has been widely regarded as the purest or most intense form of a computational process or mechanical procedure from many perspectives, including discussions of computability (Turing, 1936-37; Gödel, 1964/2004) and other disciplines, including classical experimental information retrieval and natural language processing (Wilks, Slator, and Guthrie, 1996). 
${ }^{4}$ Conceptions of computability have repeatedly and consistently appealed to the natural. Turing's own formulation of the concept of computability as 'what would naturally be regarded as computable' (Turing, 1936-1937/2004, p.135), drew on preceding thought in mathematics and mathematical logic and was also rooted in ordinary discourse and everyday experience. This characterization of computability has been accepted in subsequent logical and mathematical discourse and theoretical computer science. Natural[ly] is the specific and the dominant term. Other terms include for the concept of computability, analogous to the natural or even descending or derived from it, include particularly 'intuitive' (Church, 1936/2004, p.90; Turing, 1939/2004, p.160; Minsky, 1967, p.136; Davis, 1982, p.10, 1995, p.154; Boolos and Jeffrey, 1989, p.20; Rosen, 1995, p.524) and 'appeal[s] to intuition' (Turing, 1936-37/2004, p.249). Conceptions of computability are, then, characterized as natural, with some further incorporation of the intuitive, with these characterizations widely diffused within relevant scholarly spheres.

${ }^{5}$ Classically, and in its origins, the modeling of the computational process in mechanical terms was concerned with automatic procedures.

If at each stage the motion of a machine ... is completely determined by the configuration, we shall call the machine an 'automatic machine'. ... In this paper I deal only with automatic machines. (Turing, 1936-37/2004, p.118)

In subsequent discussions, the deliberate limitation to automatic machines has been transformed into a primary focus.

${ }^{6}$ The conception of computability as what would naturally be regarded as computable preexisted the formulation of satisfactory models of the computational process. Such a conception is an unsatisfactory or incomplete, particularly from a mathematical perspective. The models of the computational process offer a more precise characterization of the concept of computability.

Models of the computational process intended to give definite form to what would naturally be regarded as computable were made public between 1935 and 1937 by Church, Kleene, Turing, and Post (Davis, 1995; 2004). Turing's model subsequently became strongly dominant in the discourse, of mathematics, logic, and computer science (Herken, 1995), although this is of historical rather than fully theoretical significance. Different models for the computational process give rise to identical sets of computable functions.

Formulations or models of the computational process were developed with the intention of giving specific form to the concept of computability.

The purpose of the present paper is to propose a definition of effective calculability which is thought to correspond satisfactorily to the somewhat vague intuitive notion in terms of which problems of this class are often stated (Church, 1936/2004, p.90).

Models of the computational process are also advanced for their 'psychological fidelity' to the human experience of computation (Post, 1936, p.291).

In subsequent discussions, the models or definitions are regarded as giving definite form or as an 'acceptable technical counterpart' (Minsky, 1967, p.136) to what would naturally be regarded as computable. The models, particularly Turing's model, are further characterized as giving 'an absolute definition' (Gödel, 1946/2004, p.84) for the concept of computability. The models tend to be regarded as absolute accounts of the computational process, whereas the thesis is taken to appeal to natural understandings and to intuition. 